\title{
DINÂMICA DE BRACATINGAIS INEQUIÂNEOS SOB DIFERENTES CONDIÇÕES AMBIENTAIS NO PLANALTO SUL CATARINENSE
}

\author{
Paula Iaschitzki Ferreira ${ }^{*}$, Juliano Pereira Gomes ${ }^{2}$, Lilian Iara Bet Stedille ${ }^{3}$, \\ Roseli Lopes da Costa Bortoluzzi ${ }^{4}$, Adelar Mantovani ${ }^{5}$

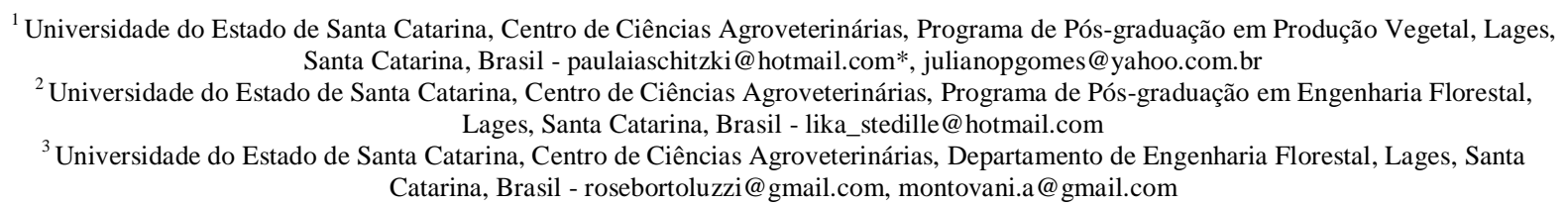

Recebido para publicação: 12/07/2016 - Aceito para publicação: 19/12/2016

\begin{abstract}
Resumo
A dinâmica das populações de plantas em uma c omunidade explica as mudanças qualitativas e quantitativas que ocorrem na vegetação, em que o balanço entre o recrutamento e mortalidade determina o funcionamento e a complexidade local, contribuindo para o entendimento das relações entre população e o meio. Objetivou-se avaliar alterações na estrutura populacional de Mimosa scabrella Benth., quanto ao recrutamento, a mortalidade e o incremento em área basal em populações com diferentes idades e verificar suas relações com variáveis ambientais. As populações avaliadas estão inseridas no Planalto Sul Catarinense, sob os domínios da Floresta Ombrófila Mista Montana (FOM-M) e Alto-Montana (FOM-A). No ano de 2012, três parcelas permanentes $(40 \times 40 \mathrm{~m})$ foram aleatoriamente alocadas em populações naturais, onde todos os indivíduos presentes foram mensurados quanto o diâmetro a altura do peito para adultos (DAP $\geq 5 \mathrm{~cm}$ ) $\mathrm{e}$ diâmetro a altura do colo (DAC) para regenerantes (DAP $<5 \mathrm{~cm}$ ), os quais foram remedidos no ano seguinte (2013). Para todas as populações foram avaliados o total de indivíduos, mortalidade, recrutamento e alterações na densidade, assim como a influência das variáveis ambientais (química do solo, declividade e abertura do dossel) sobre os valores de incremento em área basal $\left(\mathrm{m}^{2} \mathrm{ha}^{-1}\right)$. As alterações sobre a distribuição diamétrica caracterizam o caráter pioneiro de Mimosa scabrella, evidenciando o efeito da cobertura do dossel na dinâmica destas populações. Características relacionadas às maiores altitudes (FOM-A) alteraram o comportamento da espécie, influenciando os processos de dinâmica, especialmente a mortalidade, que apresentou taxa média de $10,5 \%$. Mesmo não sendo fatores limitantes para o desenvolvimento de Mimosa scabrella, a mesma apresenta resposta em termos de crescimento sob condições de fertilidade. Palavras-chave: Mimosa scabrella Benth.; distribuição diamétrica; mortalidade; área basal; heterogeneidade ambiental.
\end{abstract}

Abstract

Dynamic Mimosa scabrella Benth. populations of different ages under different environmental conditions in the Southern Plateau of Santa Catarina. The dynamics of plant populations in a community explains the qualitative and quantitative changes that occur in the vegetation, where the balance between recruitment and mortality determines the local functioning and complexity, contributing to the understanding of the relationships between population and the environment. The objective was to evaluate changes in population structure of Mimosa scabrella, as the recruitment, mortality and increase in basal area in populations with different ages and verify its relationship with environmental factors. The populations evaluated are embedded in Plateau of Santa Catarina, in the Montane Araucaria Forest (FOM-M) and Highland Araucaria Forest (FOM-A). In 2012, three plots $(40 \times 40 \mathrm{~m})$ were randomly allocated into natural populations, where all individuals present were measured as the diameter of the breast height for adults $(\mathrm{DBH} \geq 5 \mathrm{~cm})$ and diameter neck height for regenerating $(\mathrm{DNH}<5 \mathrm{~cm}$ ), which were re-measured the following year (2013). For all populations evaluated the total of individuals, mortality, recruitment and changes in density as well as the influence of environmental variables (soil chemistry, slope and canopy openness) on the gain values in basal area $\left(\mathrm{m}^{2} \mathrm{ha}^{-1}\right)$. Changes in population structure confirms the pioneering character of Mimosa scabrella, showing the effect of canopy cover on the dynamics of these populations. Characteristics related to higher altitudes (FOM-A) altered the behavior of the species, influencing the dynamics processes, especially mortality, which presented an average rate of $10.5 \%$. Although not limiting factors for the development of Mimosa scabrella, it has the same response in terms of growth under conditions fertility.

Keywords: Mimosa scabrella Benth.; diameter distribution; mortality; basal area; environmental heterogeneity.

\section{INTRODUÇÃO}

Como a maioria das tipologias do domínio atlântico, a Floresta Ombrófila Mista (FOM), uma das principais tipologias vegetais da região sul do Brasil (INSTITUTO BRASILEIRO DE GEOGRAFIA E ESTATÍSTICA (IBGE), 2012), foi intensamente alterada e fragmentada (HIGUCHI et al., 2012). Em Santa Catarina são raríssimos os remanescentes de florestas primárias, já os fragmentos de florestas secundárias de FOM, em estádio médio e avançado, compreendem 24,4\% de cobertura (SEVEGNANI et al., 2013). Assim 
torna-se notório a representatividade dos remanescentes em estágio inicial em que a sucessão florestal frequente e abundantemente é composta por bracatinga.

Mimosa scabrella Bentham é uma Fabaceae, da subfamília Mimosoideae, popularmente conhecida como bracatinga, nativa e endêmica do Brasil. Pertencente ao grupo ecológico das pioneiras, ocorre principalmente em formações secundárias de clareiras naturais ou antrópicas das matas primárias da FOM, as quais viabilizam a entrada de luz e a quebra de dormência das sementes, chegando a formar núcleos densos quase puros, que substitui gradativamente as espécies herbáceas e arbustivas dos estádios iniciais da sucessão (BURKART, 1979).

Um dos mecanismos mais importantes que controlam a regeneração florestal é a limitação no recrutamento nas fases iniciais do ciclo de vida das plantas (ALVES; METZGER, 2006). Neste sentido, a comunidade pioneira, ao fornecer novas condições ecológicas, especialmente, sombreamento (DURAES et al., 2014), caracteriza um típico modelo de facilitação ecológica, pelas alterações microambientais, como redução da radiação solar e evapotranspiração, mantendo as condições de umidade e temperatura (GUEVARA et al.,1992; CALLAWAY; WALKER, 1997; HOLMGREN et al., 1997), favoráveis para o estabelecimento de espécies mais exigentes. Entretanto, ainda existe uma lacuna de informações científicas sobre as características das populações vegetais que ocorrem naturalmente em ambiente alterados (AMARAL et al., 2013), especialmente em formações de FOM, considerando os níveis alarmantes de perda de biodiversidade.

A dinâmica das populações de plantas em uma comunidade explica as mudanças qualitativas e quantitativas que ocorrem na vegetação, em que o balanço entre o recrutamento e mortalidade determina o funcionamento e a complexidade local, contribuindo para o entendimento das relações entre população e o meio. Além disso, o conjunto destas informações permite o monitoramento e a previsão dos processos de transformação das populações e das comunidades vegetais isoladas (HIGUCHI et al., 2008), as quais poderão subsidiar ações de manejo, conservação e restauração de áreas degradadas.

Assim, considerando a escassez de informações sobre aspectos ecológicos de Mimosa scabrella e suas relações com variáveis ambientais, objetivou-se: $i$ ) avaliar alterações na estrutura populacional, recrutamento, mortalidade e incremento em área basal em populações de $M$. scabrella com diferentes idades, em dois períodos de avaliação e, ii) verificar a influência de variáveis ambientais sobre o crescimento dos indivíduos destas populações.

\section{MATERIAL E MÉTODOS}

O estudo foi realizado em fragmentos remanescentes, com presença de populações de Mimosa scabrella, localizadas no Planalto Sul Catarinense, o qual está localizado na porção central do Estado e é formado por relevo que apresenta grande variação, definindo fitofisionomias diferentes da Floresta Ombrófila Mista, conforme IBGE (2012). Para abranger um gradiente de idade entre as populações, os históricos das áreas foram previamente avaliados com base em entrevistas aos proprietários e verificação em sequências de imagens aéreas (Google Earth). A partir desta análise prévia, foram selecionadas quatro populações de $M$. scabrella, uma com nove anos inserida em Floresta Ombrófila Mista Alto-montana (FOM-A) e outras três, com idades de nove, sete e quatro anos, na formação Floresta Ombrófila Mista Montana (FOM-M).

As populações estão em áreas onde o solo é predominante do tipo Cambissolo (EMBRAPA, 2013), onde a precipitação média é de $1.200 \mathrm{~mm} / \mathrm{ano}$, com clima do tipo Cfb, conforme pela classificação de Köppen (CLIMATE, 2015) (Tabela 1).

Em todas as populações foram alocadas três unidades amostrais, com dimensões de $40 \times 40 \mathrm{~m}$ $\left(1.600 \mathrm{~m}^{2}\right)$, dividas em sub-parcelas de $10 \times 10 \mathrm{~m}$, totalizando uma área amostral 1,92 ha. No primeiro inventário, realizado em fevereiro de 2012, todos os indivíduos $M$. scabrella presentes foram identificados, plaqueteados e medidos quanto ao diâmetro à altura do peito (DAP), para indivíduos adultos (DAP $\geq 5 \mathrm{~cm}$ a $1,3 \mathrm{~m}$ de altura); e diâmetro à altura do colo (DAC), para indivíduos regenerantes (DAP $<5 \mathrm{~cm}$ a $1,3 \mathrm{~m}$ de altura). No ano seguinte (fev/2013) foram contabilizados os indivíduos recrutados, registrados os indivíduos mortos e os sobreviventes foram mensurados novamente.

As variáveis ambientais consideradas foram a caracterização química do solo, relevo (declividade) e abertura do dossel, avaliadas em cada subparcela $(10 \times 10 \mathrm{~m})$. A coleta de solo foi realizada nas camadas superficiais, a uma profundidade de 0 a $20 \mathrm{~cm}$. No laboratório foram determinadas as seguintes variáveis químicas: matéria orgânica, cálcio, magnésio, alumínio, fosforo, sódio, potássio, e calculados os índices: CTC efetiva e saturação por bases (V\%) (Tabela 1). A declividade média foi calculada a partir de valores de quatro leituras por subparcela, obtidas com o aparelho TruPulse Laser Rangefinder modelo 360. A cobertura de dossel foi avaliada com auxílio de densiômetro esférico, onde se adotou a média de quatro leituras, em direção ao norte, sul, leste e oeste, no centro de cada parcela. 
Tabela 1. Descrição das áreas e valores médios das variáveis ambientais, analisadas nas unidades amostrais, alocadas sob as populações de Mimosa scabrella Benth., com diferentes idades, localizadas no Planalto Sul Catarinense.

Table 1. Description of areas and average values of environmental variables analyzed in the sample units, allocated under the populations of Mimosa scabrella Benth., of different ages, located in the in the Southern Plateau of Santa Catarina.

\begin{tabular}{|c|c|c|c|c|}
\hline \multirow{2}{*}{$\begin{array}{l}\text { Características } \\
\text { Idade (anos) }\end{array}$} & \multicolumn{4}{|c|}{ Populações de Mimosa scabrella Benth. } \\
\hline & 4 anos & 7 anos & 9 anos & 9 anos \\
\hline Fitofisionomia $^{1}$ & FOM-M* & FOM-M $*$ & FOM-M $*$ & FOM-A** \\
\hline Coordenadas & $27^{\circ} 41^{\prime} 35^{\prime \prime} \mathrm{Se}$ & $27^{\circ} 29^{\prime} 00^{\prime \prime} \mathrm{S} \mathrm{e}$ & $27^{\circ} 47^{\prime} 00^{\prime \prime} \mathrm{S} \mathrm{e}$ & $27^{\circ} 52^{\prime} 37^{\prime \prime} \mathrm{S} \mathrm{e}$ \\
\hline geográficas & $49^{\circ} 59^{\prime} 34^{\prime \prime} \mathrm{W}$ & $50^{\circ} 17^{\prime} 11^{\prime \prime} \mathrm{W}$ & $50^{\circ} 21^{\prime} 00^{\prime \prime} \mathrm{W}$ & $49^{\circ} 55^{\prime} 14^{\prime \prime} \mathrm{W}$ \\
\hline Município & Bocaina do Sul & Ponte Alta & Lages & Urupema \\
\hline Altitude & 850 & 880 & 916 & 1.425 \\
\hline Temp. média $\left({ }^{\circ} \mathrm{C}\right)^{2}$ & 16,5 & 16,9 & 16,5 & 14,1 \\
\hline $\operatorname{MO}(\%)$ & 4,01 & 6,24 & 4,68 & 9,08 \\
\hline $\mathrm{Ca}\left(\mathrm{cmolc} \cdot \mathrm{dm}^{-3}\right)$ & 0,81 & 0,76 & 0,84 & 5,48 \\
\hline $\mathrm{Mg}\left(\mathrm{cmolc} \cdot \mathrm{dm}^{-3}\right)$ & 0,54 & 0,48 & 0,58 & 2,02 \\
\hline $\mathrm{Al}\left(\mathrm{cmolc} \cdot \mathrm{dm}^{-3}\right)$ & 6,39 & 5,68 & 3,48 & 2,47 \\
\hline $\mathrm{P}\left(\mathrm{mg} \cdot \mathrm{dm}^{-3}\right)$ & 1,80 & 5,04 & 5,50 & 7,65 \\
\hline $\mathrm{Na}\left(\mathrm{mg} \cdot \mathrm{dm}^{-3}\right)$ & 13,89 & 8,87 & 5,88 & 8,31 \\
\hline $\mathrm{K}\left(\mathrm{mg} \cdot \mathrm{dm}^{-3}\right)$ & 89,26 & 84,66 & 100,66 & 134,16 \\
\hline CTCef $\left(\mathrm{cmolc} \cdot \mathrm{dm}^{-3}\right)$ & 7,97 & 7,14 & 5,27 & 23,55 \\
\hline $\mathrm{V}(\%)$ & 5,55 & 5,37 & 4,00 & 30,35 \\
\hline Dossel (\%) & 51,79 & 25,17 & 3,11 & 22,86 \\
\hline Declividade $\left({ }^{\circ}\right)$ & 7,46 & 5,37 & 7,57 & 15,65 \\
\hline
\end{tabular}

${ }^{1}$ IBGE (1992): *FOM-M = Floresta Ombrófila Mista Montana; **FOM-A = Floresta Ombrófila Mista Alto-Montana. ${ }^{2}$ EPAGRI/CIRAM (2014). Temp.= Temperatura; $\mathrm{MO}=$ matéria orgânica; $\mathrm{Ca}=$ cálcio; $\mathrm{Mg}=$ magnésio; $\mathrm{Al}=$ alumínio; $\mathrm{P}=$ fósforo; $\mathrm{Na}=$ sódio; $\mathrm{K}=$ potássio; CTCef = CTC efetiva; $V$ = saturação por bases.

Para verificar alterações na estrutura populacional, foram avaliadas, para o total de indivíduos, a mortalidade $\left(\% \cdot\right.$ ano $\left.^{-1}\right)$, recrutamento $\left(\% \cdot\right.$ ano $\left.^{-1}\right)$ e alterações na densidade (indivíduos.ha $\left.{ }^{-1}\right)$, em todas as populações. Ainda, para abordagem demográfica da população, foram utilizados histogramas de frequência das classes de diâmetro para o conjunto total de indivíduos adultos (DAP $\geq 5$ ) e regenerantes (Diâmetro a altura do colo-DAC $\leq 5$ ), as quais foram distribuídas em intervalos de dois centímetros. Para o período avaliado observouse diferenças nas frequências de densidade relativa (\%) de cada classe, entre avaliações, utilizando o teste de aderência qui-quadrado $\left(\chi^{2}\right)$ no nível de $5 \%$ de significância. O padrão que descreve a distribuição de frequências para cada local, em cada avaliação (2012 e 2013), foi analisado utilizando um teste de aderência de KolmogorovSmirnov (K-S) ao nível de 5\% de significância. Complementarmente, correlações de Spearman foram aplicadas para avaliar se a mortalidade (inventário 2013) era dependente da densidade de indivíduos vivos no período inicial (2012).

Para todas as populações amostradas foram investigadas as alterações na estrutura populacional. Foi avaliada o total de indivíduos quanto a mortalidade $\left(\%\right.$.ano $\left.{ }^{-1}\right)$, recrutamento $\left(\%\right.$.ano $\left.{ }^{-1}\right)$, crescimento (Incremento Periódico Anual (IPA) dos DAP $\left(\mathrm{cm} \mathrm{ano}{ }^{-1}\right)$ e em área basal $\left(\mathrm{m}^{2} \cdot \mathrm{ha}^{-1} \mathrm{ano}^{-1}\right)$ e as alterações na densidade (indivíduos. $\mathrm{ha}^{-1}$ ) entre períodos avaliados. Para cada local verificou-se por meio de um teste t-pareado as diferenças das variáveis densidade (indivíduos.ha $\left.{ }^{-1}\right)$ e a área basal $\left(\mathrm{m}^{2} \cdot \mathrm{ha}^{-1}\right)$ no nível de $5 \%$ de significância, considerando os diferentes anos avaliados (2012 e 2013).

A influência das variáveis ambientais, analisada sobre o ganho em área basal $\left(\mathrm{m}^{2} \mathrm{ha}^{-1}\right)$, durante os dois períodos avaliados, foi realizada por meio de árvores de regressão multivariada (ARM) (DE'ATH, 2002), que foram "podadas" a partir do menor valor do erro de validação cruzada.

Os gráficos foram desenvolvidos no programa SIGMAPLOT versão 11.0 SigmaPlot (Systat Software, San Jose, CA). Todas as análises foram feitas no programa estatístico R (versão 2.2.1, R Development Core Team 2010), no qual foram utilizadas as bibliotecas Vegan, para calcular o Coeficiente de Correlação de Spearman e; Mvpart e Kitypart, para as análises de regressão multivariadas (ARM).

\section{RESULTADOS}

A distribuição diamétrica nos dois anos avaliados apresentaram diferenças no comportamento entre as categorias adultos e regenerantes. Diferenças significativas foram observadas em algumas classes, ao considerar 
as proporções das densidades relativas observadas entre os anos (2012 vs 2013), para a mesma classe, pelo teste do qui-quadrado ( $<$ 0,05) (Figura 1 e 2).

Entre os regenerantes, ao considerar a densidade relativa $(\%)$ nas classes de diâmetro, o teste de aderência de Kolmogorov-Smirnov (K-S) revelou a distribuição normal como a mais adequada para descrever os locais de quatro anos FOM-M para 2012 ( $\mathrm{p}=0,008)$ e de sete anos FOM-Mpara $2012(\mathrm{p}=0,003)$ e $2013(\mathrm{p}=0,005)$.
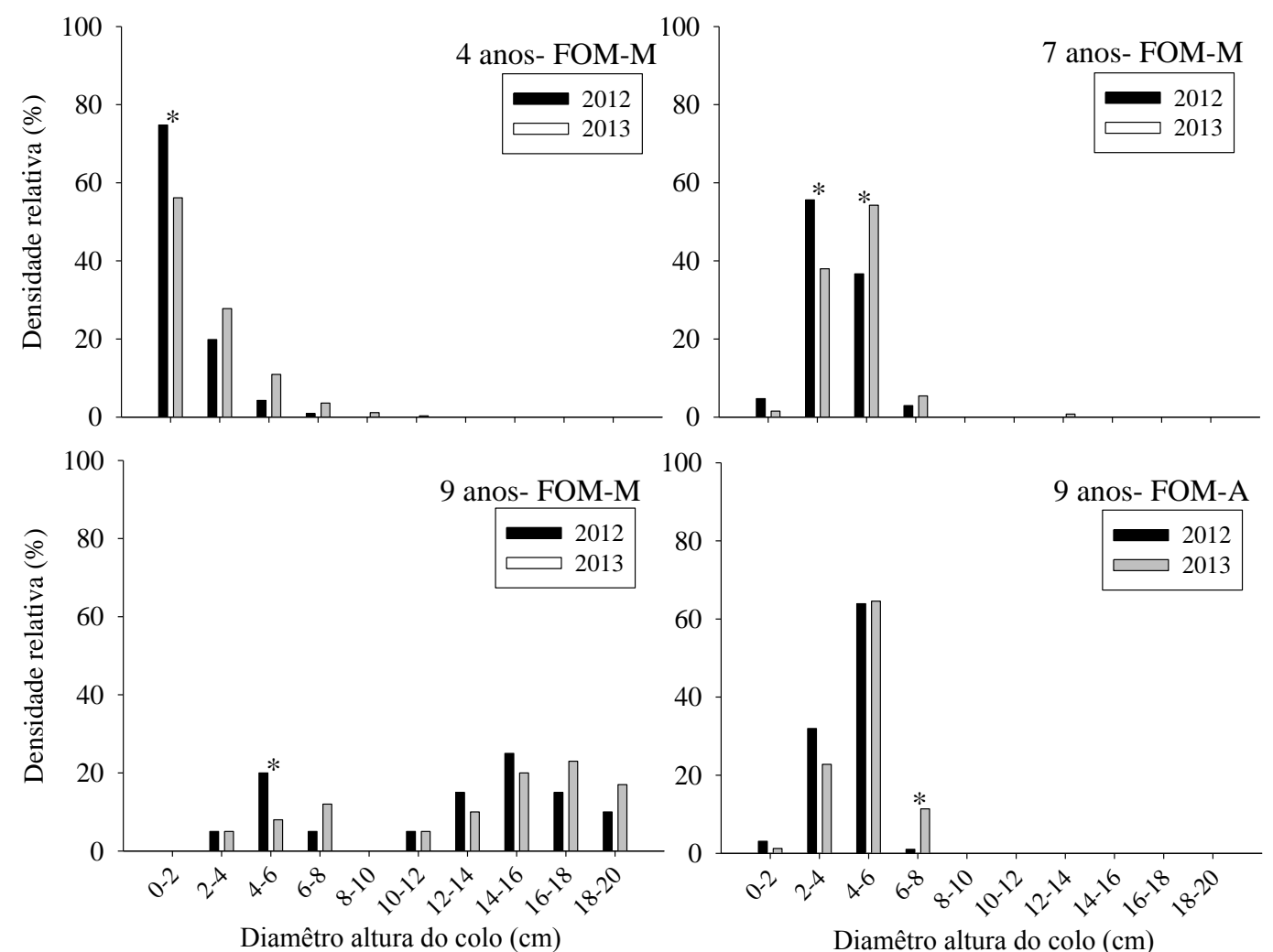

Diamêtro altura do colo $(\mathrm{cm})$

Figura 1. Distribuição diamétrica de indivíduos regenerantes de Mimosa scabrella Benth. em populações naturais com diferentes idades localizadas no Planalto Catarinense, nos inventários de 2012 e 2013. Legenda: * diferença significativa na mesma classe de diâmetro para os anos avaliados (2012 vs 2013) de acordo com o teste do qui-quadrado $(\mathrm{p}<0,05)$, restante não significativo.

Figure 1. Distribution of individuals diameter of regenerating Mimosa scabrella Benth. in natural populations of different ages located in the Plateau of Santa Catarina in 2012 and 2013 inventories. * significant difference in the same diameter class for the evaluated years (2012 vs 2013) according to the chisquare test $(\mathrm{p}<0.05)$, remaining not significant.

Entre os adultos ao considerar a densidade relativa (\%), nas classes de diâmetro, o modelo de distribuição normal define os locais: sete anos FOM-M para $2012(\mathrm{p}=0,01)$ e $2013(\mathrm{p}=<0,001)$ e nove anosFOM-A para $2012(\mathrm{p}=0,025)$ e $2013(\mathrm{p}=0,014)$. 

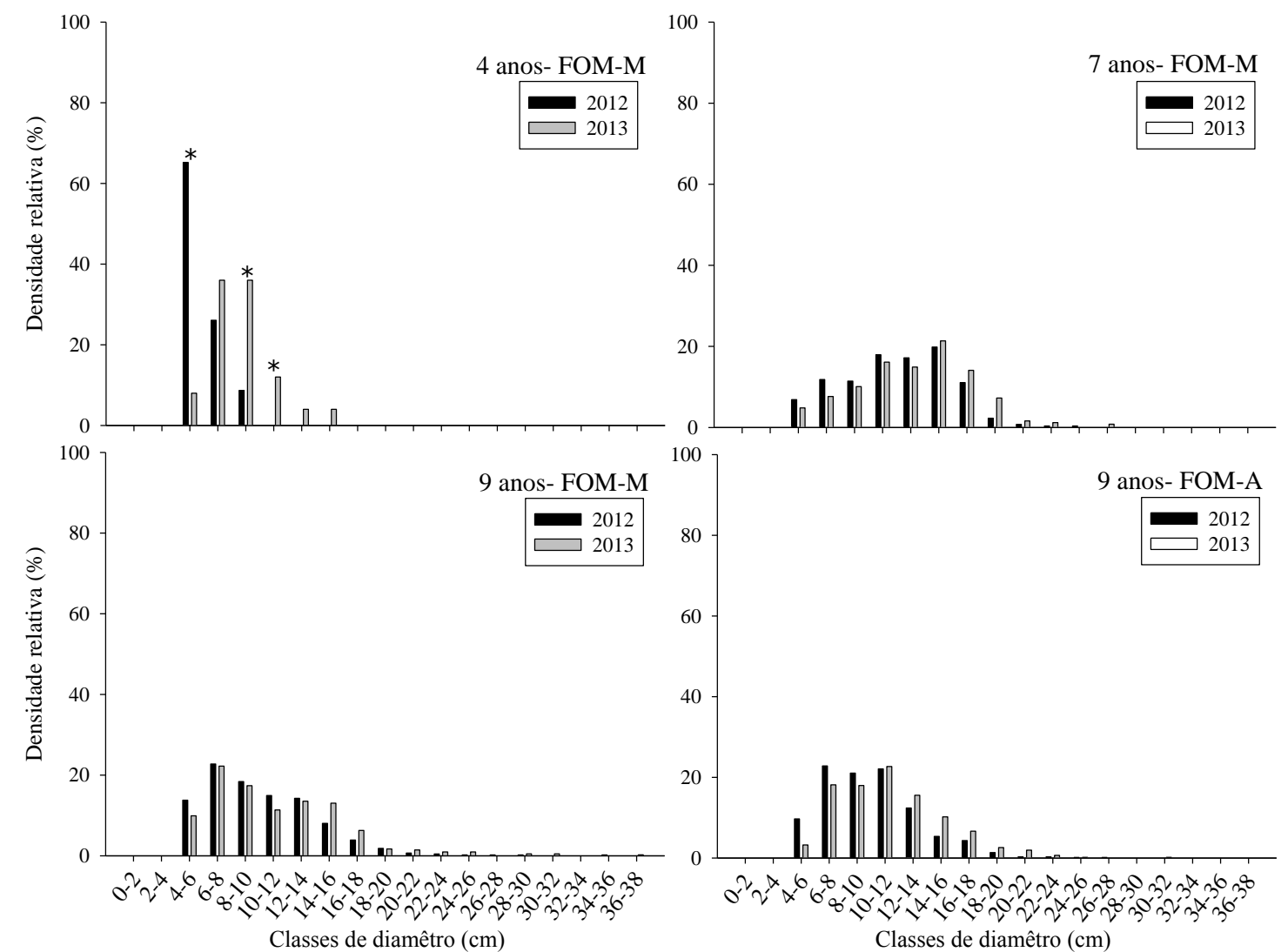

Figura 2. Distribuição diamétrica de indivíduos adultos de Mimosa scabrella Benth. em populações naturais com diferentes idades localizadas no Planalto Catarinense, nos inventários de 2012 e 2013. * diferença significativa na mesma classe de diâmetro para os anos avaliados (2012 vs 2013) de acordo com o teste do qui-quadrado $(\mathrm{p}<0,05)$, restante não significativo.

Figure 2. Distribution of individuals diameter of adult Mimosa scabrella Benth. in natural populations of different ages located in the Plateau of Santa Catarina in 2012 and 2013 inventories. * significant difference in the same diameter class for the evaluated years (2012 vs 2013) according to the chisquare test $(\mathrm{p}<0.05)$, remaining not significant.

Os valores de densidade e mortalidade registrados para a população sob ambiente alto-montano (nove anos, FOM-A) foram semelhantes à população de sete anos (FOM-M) e, apenas na população de quatro anos foi observado correlação significativa $(p<0,01)$ entre a taxa de mortalidade e densidade de indivíduos (Tabela 2).

Tabela 2. Densidade, área basal, mortalidade, recrutamento e crescimento das populações de Mimosa scabrella Benth., com diferentes idades, localizadas no Planalto Sul Catarinense.

Table 2. Density, basal area, mortality, recruitment and growth in populations of Mimosa scabrella Benth., of different ages, located in the in the Southern Plateau of Santa Catarina.

\begin{tabular}{|c|c|c|c|c|}
\hline \multirow{2}{*}{ Avaliação } & $4 \operatorname{anos}($ FOM-M) & $7 \operatorname{anos}(\mathrm{FOM}-\mathrm{M})$ & $9 \operatorname{anos}($ FOM-M) & 9 anos (FOM-A) \\
\hline & \multicolumn{4}{|c|}{ Densidade populacional (Ind.ha ${ }^{-1}$ ) } \\
\hline 2012 & 3758,33 & 656,25 & 440,63 & 731,25 \\
\hline \multirow[t]{2}{*}{2013} & 3229,17 & 583,33 & 421,88 & 654,17 \\
\hline & \multicolumn{4}{|c|}{ Área basal de indivíduos adultos $\left(\mathrm{m}^{3} \cdot \mathrm{ha}^{-1}\right)$} \\
\hline 2012 & 3,59 & 14,47 & 10,14 & 12,33 \\
\hline \multirow[t]{2}{*}{2013} & 7,20 & 16,74 & 11,81 & 15,22 \\
\hline & \multicolumn{4}{|c|}{ Taxa de mortalidade (\%) } \\
\hline $2012 / 2013$ & $14,08^{*}$ & 11,11 & 4,26 & 10,54 \\
\hline
\end{tabular}

FLORESTA, Curitiba, PR, v. 47, n. 1, p. 43 - 54, jan. / mar. 2017.

Ferreira, P. I. et al.

ISSN eletrônico 1982-4688

DOI: $10.5380 /$ rf.v47i1.45263 


\begin{tabular}{lcccc}
\hline \multicolumn{5}{c}{ Recrutamento (Ind.ha $^{\mathbf{- 1}}$ ) } \\
\hline $2012 / 2013$ & 0 & 0 & 0 & 0 \\
\hline \multicolumn{5}{c}{ Incremento Periódico Anual (IPA) em DAP de indivíduos adultos (cm)** } \\
\hline $2012 / 2013$ & 2,99 & 1,18 & 1,06 & 1,07 \\
\hline $2012 / 2013$ & Incremento Periódico Anual (IPA) em Área basal de indivíduos adultos $\left(\mathbf{m}^{\mathbf{2}} \mathbf{h a}^{\mathbf{- 1}}\right)^{* *}$ \\
\hline
\end{tabular}

* correlação significativa $(\mathrm{p}<0,01)$ entre a taxa de mortalidade e densidade de indivíduos;

** neste trabalho igual ao Incremento Corrente Anual (ICA).

Entre os anos de 2012 e 2013, o teste t-pareado ( $p<0,05$ ), permitiu aferir a existência de diferenças significativas na densidade (indivíduos.ha ${ }^{-1}$ ) considerando as populações avaliadas $(\mathrm{n}=4)$, no entanto, a área basal não apresentou diferenças.

As variáveis ambientais, analisadas sobre o ganho em área basal, demonstraram relação com a cobertura do dossel na população com quatro anos, em FOM-M (Figura 3), com a declividade na população com sete anos, em FOM-M (Figura 4), teores de fósforo na população com nove anos, em FOM-M, (Figura 5) e saturação de bases na população com nove anos, em FOM-A (Figura 6).

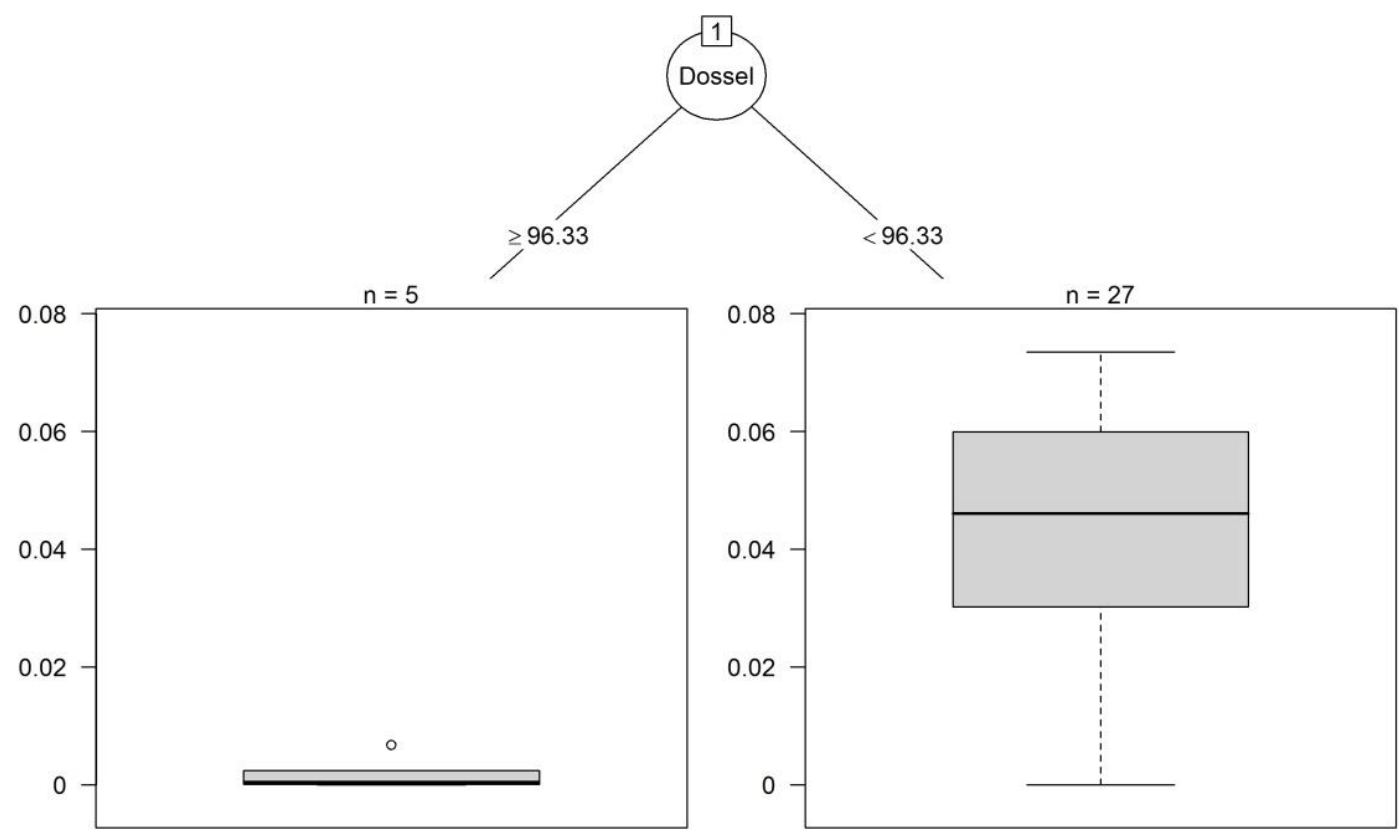

Figura 3. Árvore de regressão múltipla para ganho em área basal em populações de Mimosa scabrella Benth, com quatro anos de idade, Floresta Ombrófila Mista Montana (FOM-M), valor do Erro Relativo (ER) $=0,56$ e Erro de validação cruzada $($ ERVD) $=0,85$.

Figure 3. Regression multiple trees to gain basal area in populations of Mimosa scabrella Benth, with four years of age, Montane Araucaria Forest (FOM-M), value of Relative Error (ER) = 0,56 e Cross-validation Error $($ ERVD $)=0,85)$. 


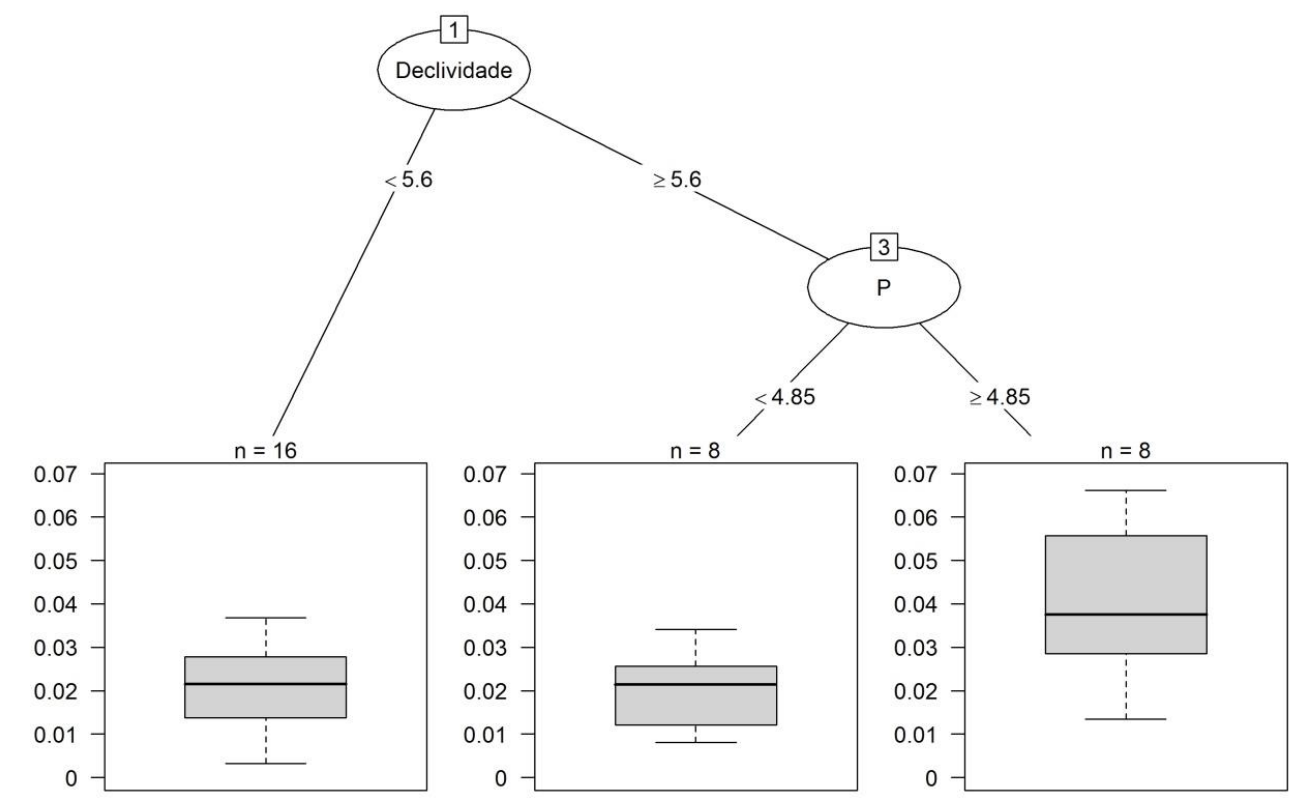

Figura 4. Árvore de regressão múltipla para ganho em área basal em populações de Mimosa scabrella Benth, com sete anos de idade, Floresta Ombrófila Mista Montana (FOM-M), valor do Erro Relativo $($ ER $)=$ 0,72 e Erro de validação cruzada $(\mathrm{ERVD})=2,65$.

Figure 4. Regression multiple trees to gain basal area in populations of Mimosa scabrella Benth, with seven years of age, Montane Araucaria Forest (FOM-M), value of Relative Error (ER) $=0,72$ e Crossvalidation Error $(\mathrm{ERVD})=2,65$.

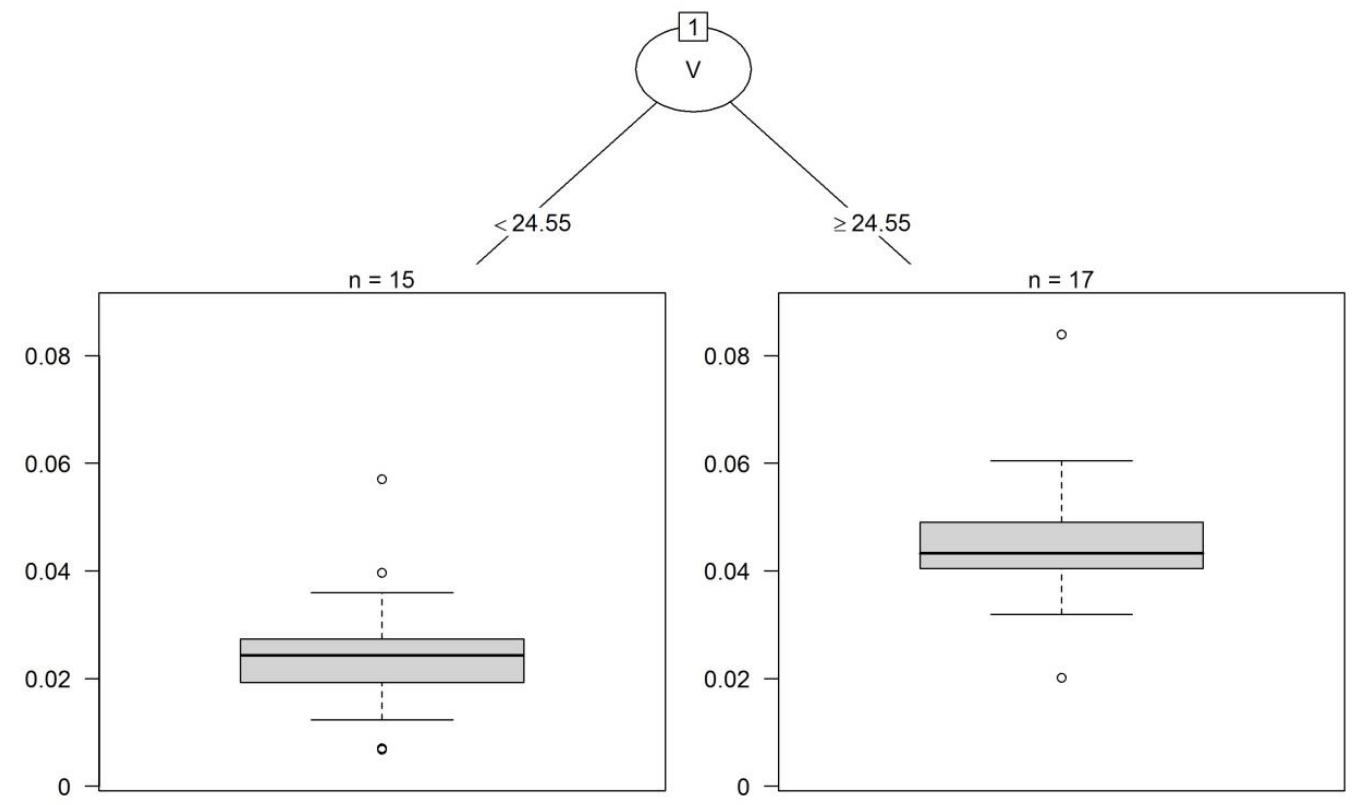

Figura 5. Árvore de regressão múltipla para ganho em área basal em populações de Mimosa scabrella Benth, com nove anos de idade, Floresta Ombrófila Mista Alto-Montana (FOMA), valor do Erro Relativo $(E R)=0,75$ e Erro de validação cruzada $(E R V D)=1,61$.

Figure 5. Regression multiple trees to gain basal area in populations of Mimosa scabrella Benth, with nine years of age, Highland Araucaria Forest (FOM-A), value of Relative Error (ER) = 0,75 e Crossvalidation Error $(E R V D)=1,61$. 


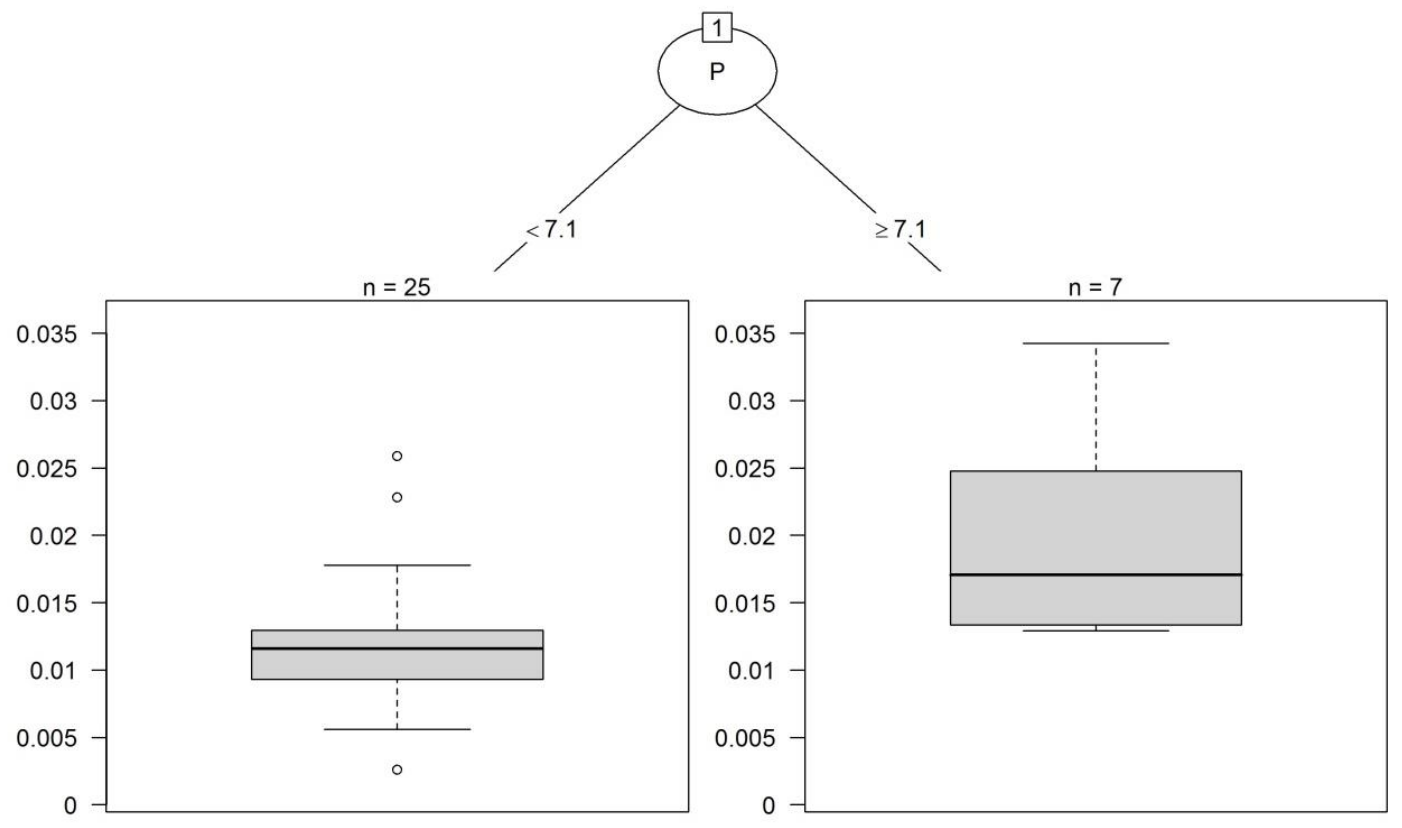

Figura 6. Árvore de regressão múltipla para ganho em área basal em populações de Mimosa scabrella Benth, com nove anos de idade, Floresta Ombrófila Mista Montana (FOM-M), valor do Erro Relativo (ER) = 0,61 e Erro de validação cruzada (ERVD) $=1,47$.

Figure 6. Regression multiple trees to gain basal area in populations of Mimosa scabrella Benth, with nine years of age, Montane Araucaria Forest (FOM-M), value of Relative Error (ER) =0,61 e Crossvalidation Error $($ ERVD) $=1,47$.

\section{DISCUSSÃO}

A alta concentração de indivíduos, nas primeiras classes diamétricas, registrada na população mais jovem (com quatro anos, em FOM-M) foi resultado de recente exposição do banco de sementes à luminosidade, estimulando a germinação das sementes e colonização da área exposta, assim como observado por Machado et al. (2006). Nesta população foi observada diferença significativa na densidade entre os diferentes anos de avaliação para as primeiras classes diamétricas.

A correlação significativa entre a taxa de mortalidade e densidade de indivíduos observada na população mais jovem (quatro anos) indica a associação entre as mesmas, sugerindo que os valores elevados de mortalidade são inerentes aos altos níveis de densidade populacional, possivelmente oriundos da competição intraespecífica. Machado et al. (2006) também ressaltaram que o ritmo de mortalidade natural em bracatingais nativos é muito intenso nos primeiros anos de vida, sendo afetado principalmente pela densidade inicial. Kramer e Kozlowski (1972) citam que este resultado é comum a indivíduos que vivem em povoamentos densos, onde se estabelecem em cenário de competição contínua em função da luz, e, no solo, por água, minerais e oxigênio, sendo as necessidades individuais ampliadas à medida que os indivíduos aumentam de tamanho.

Para as demais populações (sete e nove anos), com ausência de formação de banco de plântulas nos dois inventários (2012 e 2013), definiu-se o padrão de distribuição normal, observando-se que o avanço para as classes subsequentes ocorre de forma gradativa e conjunta, caracterizando uma população equiânea, conforme o teste de aderência de K-S. Machado et al. (2006) registraram os efeitos da idade da população sobre a distribuição diamétrica de M. scabrella, onde o aumento do diâmetro e a redução drástica do número de árvores por hectare, tendem a deslocar as curvas para a direita à medida que o povoamento se torna mais velho. Este comportamento é comum em povoamentos equiâneos, já registrados para espécies exóticas, como a exemplo do gênero Pinus (TEO et al., 2011), e também para Cryptomeria japonica (L. F.) Don. (DOBNER JUNIOR et al., 2013).

Assim, como registrado para M. scabrella (Figura 2), a densidade populacional tende a reduzir com o avanço da idade. O regime de distúrbio, caracterizado pela ocorrência de eventos naturais e por ações antrópicas, resultam em alterações na floresta, a exemplo da luminosidade, que influencia na dinâmica de populações. Foi possível detectar o efeito da cobertura do dossel, o qual está diretamente relacionado com a interceptação e incidência luminosa, determinando o comportamento das populações de $M$. scabrella. Este resultado corrobora 
com outros estudos que têm avaliado a influência da luz na dinâmica florestal, assim como no desenvolvimento de populações (SANQUETTA et al., 2007; MARCON et al., 2014). Para espécies pioneiras, tipicamente heliófitas, a luz torna-se um fator determinante no ciclo de vida (CARVALHO et al., 2010), resultando em baixa densidade de indivíduos jovens no sub-bosque devido as condições de baixa luminosidade. Dessa forma, especialmente para bracatinga, é possível concluir que a própria população já estabelecida atua como barreira, reduzindo a luminosidade do subdossel e impedindo a germinação e formação de novo banco de plântulas, definindo-as como populações equiâneas.

A este aspecto podem ser atribuídos os valores de densidade e mortalidade registrados para a população sob ambiente alto-montano (nove anos, em FOM-A), semelhantes à população de sete anos (em FOM-M) (Figura 2). A altitude pode influenciar consideravelmente no crescimento de populações (COOMES; ALLEN, 2007), entretanto não é um fator limitante para o desenvolvimento de $M$. scabrella. As variações altitudinais estão associadas, principalmente, a mudanças de temperatura e umidade do ar (KÖRNER, 2007). Dentre estas, especialmente a temperatura exerce influência sob processos fisiológicos (PEREIRA et al., 2002), como fotossíntese, respiração, transpiração e divisão celular. As características relacionadas a maiores altitudes podem alterar os processos fisiológicos desta espécie, reduzindo o ritmo de crescimento e contribuindo para a redução de taxas de mortalidade, retardando os processos de dinâmica para esta população.

De maneira geral, a baixa densidade registrada para a população de nove anos (FOM-M) em detrimento das outras populações avaliadas, indica o caráter pioneiro da bracatinga, a qual tende a reduzir expressivamente o número de indivíduos na floresta durante o desenvolvimento da sucessão florestal. Esta redução não ocorre de forma abrupta e com maior grau de ocupação de indivíduos de outras espécies aproximadamente dos 13 aos 20 anos da floresta (STEENBOCK et al., 2011). Este aspecto pode ser atribuído ao potencial facilitador de $M$. scabrella, que ao ocupar áreas alteradas, fornece rápida cobertura do solo e contribui para a melhoria das condições ambientais de sítio sombreamento e retenção de umidade. Devido a acelerada dinâmica populacional, evidenciada no presente estudo, poderá contribuir para a melhoria das condições edáficas, incrementando a ciclagem de nutrientes favorecendo o desenvolvimento de processos ecológicos envolvidos na sucessão florestal.

No caso da população mais jovem (quatro anos), que apresentou relação entre ganho em área basal e cobertura do dossel, a alta densidade de indivíduos contribuiu para o fechamento do dossel, resultando em altos níveis de competição e mortalidade. Alguns estudos têm demonstrado diferenças entre taxas de crescimento influenciadas pela intensidade luminosa (SILVA et al., 2007; CARON et al., 2014). A quantidade de radiação fotossinteticamente ativa, que é maior em áreas sob menor cobertura do dossel, tem importância vital no desenvolvimento de plantas (SALAMI et al., 2014), revelando tendências à diminuição do incremento médio em DAP à medida que decresce a quantidade de luz recebida pelas copas.

Os maiores ganhos em área basal registrados para a população de sete anos (em FOM-M) estão associados às áreas onde há maiores alterações/depressões topográficas (declividade), relacionadas à presença de pequenos cursos d'água, e fertilidade (teores de fósforo). Fatores topográficos são considerados importantes filtros ambientais, pois assumem importante posição na definição das propriedades dos solos, regime de água e fertilidade (RODRIGUES et al., 2007).

Em termos de fertilidade do solo, os processos de ciclagem de nutrientes são influenciados diretamente por alterações de umidade, que irão variar entre as áreas mais elevadas (menor umidade) e as partes mais baixas (maior umidade) (FISK et al., 1998). Pode-se concluir, que nesta população, o maior acúmulo e disponibilidade de nutrientes ocorrentes nas áreas mais declivosas, somados à manutenção da umidade, favoreceram o crescimento em área basal dos indivíduos de M. scabrella.

Atributos relacionados à fertilidade do solo também definiram os maiores ganhos em área basal, para as populações com nove anos. Naquela sob influência do ambiente alto-montano, o ganho em área basal foi verificado nas áreas onde há maior saturação por bases (V\%) (Figura 2c), sendo estas as áreas que apresentaram os maiores valores médios desta variável $(\mathrm{V}=30,3 \%)$. Considerada como excelente indicativo de fertilidade do solo, a saturação por bases, tem sido relacionada ao crescimento de espécies florestais (FAVARE et al., 2012).

Para a população de nove anos, sem a influência do ambiente alto-montano (FOM-M), os maiores ganhos em área basal foram relacionados aos maiores teores de fósforo $\left(\geq 7,1 \mathrm{mg} \cdot \mathrm{dm}^{-3}\right)$ (Figura $\left.2 \mathrm{~d}\right)$. O efeito do fósforo no desenvolvimento de bracatinga já foi evidenciado por Vogel et al. (2001). Poggiani et al. (1987) estudaram o efeito da deposição dos nutrientes sobre o solo a partir da queda das folhas de populações de Eucalyptus viminalis Labill, Pinus taeda L. e M. scabrella, concluindo que os conteúdos de biomassa seca, nitrogênio, fósforo e potássio do folhedo depositado foram significativamente maiores no talhão de M. scabrella. Neste contexto, é possível sugerir que o acréscimo de fósforo e de outros nutrientes seja impulsionado ao longo do processo sucessional, assim como nas populações mais maduras de $M$. scabrella, em que possivelmente a ciclagem de nutrientes apresenta dinâmica mais acelerada, favorecida pela maior produção de serapilheira. 


\section{CONCLUSÕES}

- A alta concentração de indivíduos nas primeiras classes de idade, registrada na população mais jovem, e o avanço para as classes subsequentes de forma gradativa e conjunta nas populações mais maduras, confirmam o caráter pioneiro de Mimosa scabrella (bracatinga), evidenciando o efeito da luminosidade em função da cobertura do dossel sobre a dinâmica destas populações.

- Bracatingais em estágios iniciais apresentam maiores taxas de crescimento (área basal) e mortalidade decrescendo com a maturação da população. Destaca-se um comportamento diferenciado para a população da formação Alto-Montana, onde a redução do crescimento é mais tardia. Não foi observado recrutamento para o período avaliado.

- Em cada estágio de desenvolvimento dos bracatingais observa-se influência de diferentes recursos ambientais, onde populações mais jovens possuem maior dependência da cobertura do dossel e as mais maduras das condições de fertilidade do solo.

\section{AGRADECIMENTOS}

Os autores agradecem à FAPESC (Fundação de Amparo à Pesquisa e Inovação do Estado de Santa Catarina), ao FUMDES (Fundo de Apoio à Manutenção e ao Desenvolvimento da Educação Superior) e a empresa Klabin SA.

\section{REFERÊNCIAS}

ALVES, L. F.; METZGER, J. P. Forest regeneration in secondary forest areas at Morro Grande Forest Reserve, Cotia, SP. Biota Neotropica, v. 6, 2006.

AMARAL, L. P.; FERREIRA, R. A.; WATZLAWICK, L. F.; LONGHI, S. J.; SEBEM, E. Influência da floresta alterada na distribuição espacial de três espécies da Floresta Ombrófila Mista avaliada pela geoestatística. Revista Árvore, Viçosa, v. 37, n. 3, p. 491-501, 2013.

BURKART, A. Leguminosas Mimosoídeas. In: REITZ, R. (Ed.). Flora Ilustrada Catarinense. Itajaí: Herbário Barbosa Rodrigues, 1979. 304 p.

CALAWAY, R. M.; WALKER, L. R. Competition and facilitation: a synthetic approach to interactions in plant communities. Ecology, v. 78, n. 7, p. 1958-1965, 1997.

CARON, B. O.; SANTOS, D. R. dos; SCHMIDT, D.; BASSO, C. J.; BEHLING, A.; ELOY, E.; BAMBERG, R. Biomassa e acúmulo de nutrientes em Ilex paraguariensis A.St.Hil. Ciência Florestal, Santa Maria, v. 24, n. 2, p. 267-276, 2014.

CARVALHO, F. A.; FAGG, C. W.; FELFILI, J. M. Dinâmica populacional de Acacia tenuifolia (L.) Willd. em uma floresta decidual sobre afloramentos calcários no Brasil Central. Scinetia Forestalis, Piracicaba, v. 38, n. 86, p. 297-306, 2010.

CLIMATE.DATA.ORG(CLIMATE).Dados climáticos para as cidades mundiais. Disponível em: <http://http://pt .climate-data.org/>. Acesso em: 16/01/2015.

COOMES, D. A.; ALLEN, R. B. Effects of size, competition and altitude on tree growth. Journal of Ecology, v. 95, p. 1084-1097, 2007.

DE'ATH, G. Multivariate regressions trees: a new technique for modeling species-environment relationships. Ecology, Ithaca, v. 83, n. 4, p. 1105-1117, 2002.

DOBNER JUNIOR, M.; TRAZZI, P. A.; HIGA, A. R.; ARCE, J. E. Crescimento de um povoamento de Cryptomeria japônica no Sul do Brasil. Scientia Forestalis, Piracicaba, v. 41, n. 97, p. 39-46, 2013.

DURÃES, M. C. O.; SALES, N. L. P.; NETO, S. A; FIGUEIREDO, M. A. P. Levantamento florístico do estrato arbóreo de três fragmentos de floresta ciliar como subsídio à recomposição da vegetação do Rio Cedro, Montes Claros - MG. Ciência Florestal, v. 24, n. 1, p. 47-58, 2014.

EMPRESA DE PESQUISA AGROPECUÁRIA E EXTENSÃO RURAL DE SANTA CATARINA (EPAGRI/CIRAM). Centro de Informações de Recursos Ambientais e de Hidrometeorologia de Santa Catarina. Disponível em: <http://ciram.epagri.sc.gov.br> Acesso em: 15 de mar. 2014. 
FAVARE, L. G.; GUERRINI, I. A.; BACKES, C. Níveis crescentes de saturação por bases e desenvolvimento inicial de teca em um Latossolo de textura média. Ciência Florestal, Santa Maria, v. 22, n. 4, p. 693-702, 2012.

FISK, M. C.; SCHMIDT, S. K.; SEASTEDT, T. R. Topographic patterns of above- and belowground production and nitrogen cycling in alpine tundra. Ecology, v. 79, p. 2253-2266, 1998.

GUEVARA, S.; MEAVE, J.; MORENO-CASSOLA, P.; LABORDE, J. Floristic composition and structure of vegetation under isolated tress in neotropical pastures. Journal of Vegetation Science, v. 3, p. 655-664, 1992.

HIGUCHI, P.; OLIVEIRA-FILHO, A. T.; SILVA, A. C. da; MACHADO, E. L. M.; SANTOS, R. M. dos; PIFANO, D. S. Dinâmica da comunidade arbórea em um fragmento de floresta estacional semidecidual montana em Lavras, Minas Gerais, em diferentes classes de solos. Revista Árvore, Viçosa, v. 32, n. 3, p. 417-426, 2008.

HIGUCHI, P.; SILVA, A. C. da; FERREIRA, T. S.; SOUZA, S. T.; GOMES, J. P.; SILVA, K. M. da; SANTOS, K. F. dos; LINKE, C.; PAULINO, P. S. Influência de variáveis ambientais sobre o padrão estrutural e florística do componente arbóreo, em um fragmento de Floresta Ombrófila Mista Montana em Lages, SC. Ciência Florestal, Santa Maria, v. 22, n. 1, p. 79-90, 2012.

HOLMGREN, M.; SCHEFFER, M.; HUSTON, M. A. The interplay of facilitation and competition in plant communities. Ecology, v. 78, n. 7, p. 1966-1975, 1997.

INSTITUTO BRASILEIRO DE GEOGRAFIA E ESTATÍSTICA (IBGE) Manual técnico da vegetação brasileira. 2. ed. Rio de Janeiro. 275 p. Série: Manuais técnicos em geociências, n. 1, 2012.

KÖRNER, C. The use of 'altitude' in ecological research. Trends in ecology \& evolution, v. 22, n. 11, p. 569574, 2007.

KRAMER, P. J.; KOZLOWSKI, T. T. Fisiologia das árvores. Lisboa: Fundação Calouste Gulbekian, 1972, 745 p.

MACHADO, S. A.; PLÁCIDO, A. C.; BARTOSZECK, S.; FIGUEIREDO FILHO, A.; OLIVEIRA, E. B. de. Dinâmica da distribuição diamétrica de bracatingais na região metropolitana de Curitiba. Revista Árvore, v. 30 , n. 5, p. 759-768, 2006.

MARCON, A. K.; SILVA, A. C.; HIGUCHI, P.; FERREIRA, T. S.; MISSIO, F. F.; SALAMI, B.; DALLA ROSA, A.; NEGRINI, M.; BENTO, M. A.; BUZZI JÚNIOR, F. Variação florístico-estrutural em resposta à heterogeneidade ambiental em uma floresta nebular em Urubici, Planalto Catarinense. Scientia Forestalis, Piracicaba, v. 42, n. 103, p. 439-450, 2014.

PEREIRA, A. R.; PEREIRA, A. R.; ANGELOCCI, L. R.; SENTELHAS, P. C. Agrometeorologia fundamentos e aplicações práticas. Guaíba- RS: Agropecuária, 2002. 478 p.

POGGIANI, F.; ZAMBERLAN, H.; MONTEIRO, E. JR.; GAVA, I. C. Quantificação da deposição de folhedo em talhões experimentais de Pinus taeda, Eucalyptus grandis e Mimosa scabrella plantados em uma área degradada pela mineração do xisto betuminoso. IPEF, Piracicaba, n. 37, p. 21-29, 1987.

RODRIGUES, L. A.; CARVALHO, D. A.; OLIVEIRA FILHO, A. T.; CURI, N. Efeitos de solos e topografia sobre a distribuição de espécies arbóreas em um fragmento de floresta estacional semidecidual, em Luminárias, MG. Revista Árvore, v. 31, n. 1, p. 25-35, 2007.

SALAMI, B.; HIGUCHI, P.; SILVA, A. C.; FERREIRA, T. S.; MARCON, A. K.; BUZZI JÚNIOR, F.; BENTO, M. A. Influência de variáveis ambientais na dinâmica do componente arbóreo em um fragmento de Floresta Ombrófila Mista em Lages, SC. Scientia Forestalis, Piracicaba, v. 42, n. 102, p. 197-207, 2014.

SANQUETTA, C. R.; DALla CÔRTE, A. P.; SALZMANN, A. M.; VUlCANIS, L. Dinâmica de um remanescente de Floresta Ombrófila Mista no sul do Paraná sob influência de taquaras. Revista Ambiência, v. 3, n. 1, p. 65-78, 2007.

SEVEGNANI, L.; VIBRANS, A. C.; GASPER, A. L. Considerações finais sobre a Floresta Ombrófila Mista em Santa Catarina. In: VIBRANS, A. C.; SEVEGNANI, L.; GASPER, A. L.; LINGNER, D. V. (orgs.). Inventário Florístico Florestal de Santa Catarina: Floresta Ombrófila Mista. Blumenau: Edifurb, 2013. 440 p.

SILVA, B. M. DA S.; LIMA, J. D.; VAL, V. A. Efeito da luz no crescimento de mudas de Hymenaea parvifolia Huber. Revista Árvore, v. 31, n. 6, pp. 1019-1026, 2007.

STEENBOCK, W.; SIMINSKI, A.; FANTINI, A. C.; REIS, M. S. dos. Ocorrência da bracatinga (Mimosa scabrella Benth.) em bracatingais manejados e em florestas secundárias na região do planalto catarinense.

FLORESTA, Curitiba, PR, v. 47, n. 1, p. 43 - 54, jan. / mar. 2017.

Ferreira, P. I. et al.

ISSN eletrônico 1982-4688

DOI: $10.5380 /$ rf.v47i1.45263 
Revista Árvore, v. 35, n. 4, pp. 845-857, 2011.

TEO, S. J.; ROCHA, S. P. DA; BORTONCELlO, A. C.; PAZ, R. A.; COSTA, R. H. da. Dinâmica da distribuição diamétrica de povoamentos de Pinus taeda, na região de Caçador, SC. Pesquisa Florestal Brasileira, Colombo, v. 31, n. 67, p. 183-192, 2011.

VOGEL, H. L. M.; SCHUMACHER, M.; CECONI, D. Efeito de diferentes doses de fósforo no crescimento de plantas de Mimosa scabrella Bentham (Bracatinga). In: CONGRESSO BRASILEIRO DE CIÊNCIAS DO SOLO, 28., 2001, Londrina. Anais... Sociedade Brasileira de Ciências do Solo, 2001. 149 p. 